\title{
Insight into the Mesopore Formation in Zeolites by Operando and 3D Electron Microscopy
}

\author{
$\underline{\text { Valentina Girelli Consolaro }}^{1,2}$, Walid Baaziz ${ }^{1}$, Virgile Rouchon ${ }^{2}$, and Ovidiu Ersen ${ }^{1}$ \\ ${ }^{1}$ Institut de Physique et Chimie de Matériaux de Strasbourg, UMR 7504 CNRS - Université de \\ Strasbourg, 23 rue du Loess BP 43, F-67034 Strasbourg, France. \\ 2 IFP Energies nouvelles, Rond-point de l'échangeur de Solaize, BP3, 69360 Solaize, France.
}

Zeolites represent one of the key compounds in the evolution of the materials science. Thanks to their intrinsic microporosity arising from their crystalline structure, this category of aluminosilicate can be very suitable for potential use as heterogeneous catalyst. In this framework, from refining processes to biomass conversion, zeolites combine mass transport properties with solid acidity and ionic exchange.

In order to tailor these features accordingly with the application of interest, the zeolite undergoes a hydrothermal treatment - steaming and acid leaching - which aims to extract the aluminum from the crystalline sites. The process, also known as dealumination, induces the formation of a hierarchical porosity: mesoporous (ranging between 2 and $50 \mathrm{~nm}$ diameter) channels and cavities are meant to appear [1].

In this study, an environmental TEM-based approach was used for investigating the nucleation and the growth processes of the defects inside a Faujasite Y (CBV300, Zeolyst) zeolite submitted to a mix of water vapor $(16 \%)$ and $\mathrm{Ar}(84 \%)$ at 100 Torr between $620^{\circ} \mathrm{C}$ and $750{ }^{\circ} \mathrm{C}$. The observed kinetics and structural evolution are then compared with the results deduced from theoretical model or ex-situ analysis, their combined analysis providing thus a step by step description of the dealumination mechanism [2]. In parallel, a precise determination of the global morphology and surface topography of the dealuminated zeolite was obtained by STEM Electron Tomography, with a particular focus on the quantification of the porous network in relation with the crystalline structure [3].

We will show how these studies, through the first obtained results, may provide reliable information on the influence of the zeolites treatment on their subsequent structural properties. A particular attention will be given to the monitoring of the humidity rate during the hydrothermal treatment and to the occurrence of the irradiation damages, as a function of the electron exposure, which are key aspects in order to be able to totally control the specimen environment and to limit the unsuited events.

\section{References:}

[1] D Verboekend et al, Chem. Soc. Rev. 45 (2016), p. 3331.

[2] S van Donk et al, Catalysis Reviews 45 (2003), p. 297.

[3] J Zecevic et al, Angew. Chem. Int. Ed. 51 (2012), p. 4213. 


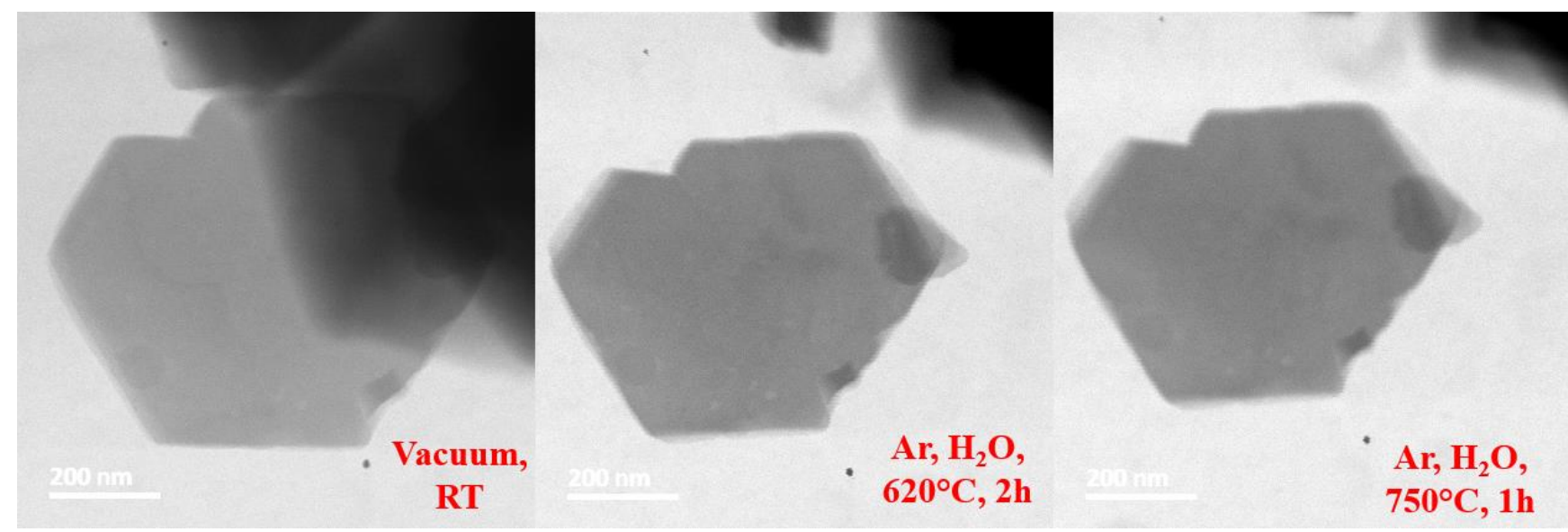

Figure 1. In situ Bright Field STEM analysis of the evolution of a typical CBV300 grain monitored under operando conditions. Left: under vacuum at room temperature. Middle: under Ar and water vapor after $2 \mathrm{~h}$ at $620^{\circ} \mathrm{C}$ (first steaming step). Right: under Ar and water vapor after $1 \mathrm{~h}$, for the second steaming at $750^{\circ} \mathrm{C}$.

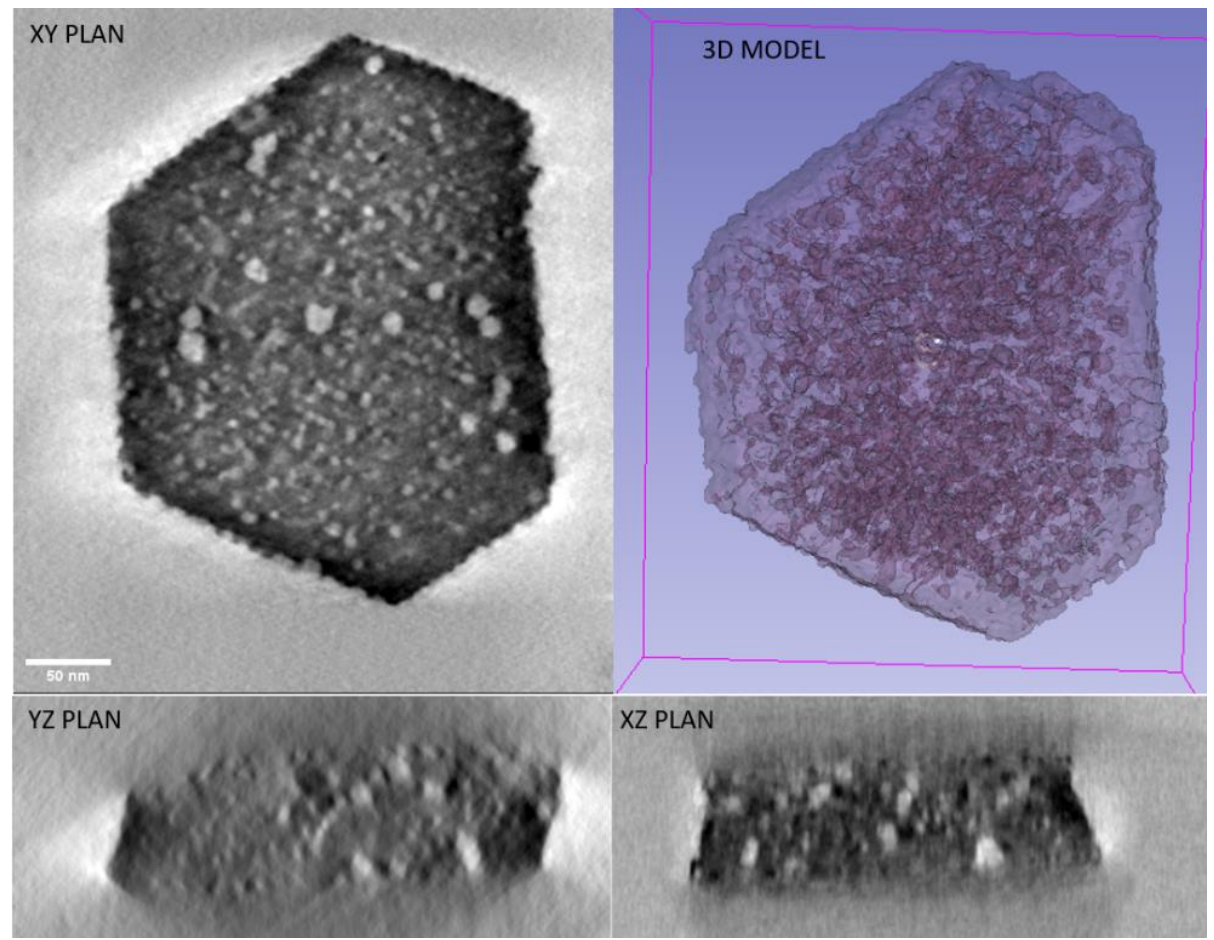

Figure 2. Reconstruction and volume modeling of a typical grain of desaluminated zeolite analyzed by electron tomography. The scale bar is the same in all the orthogonal slices. 